\title{
Iron physiological requirements in Chinese adults assessed by the stable isotope labeling technique
}

Jie Cai', Tongxiang Ren², Yuhui Zhang ${ }^{3}$, Zhilin Wang ${ }^{3}$, Lingyan Gou ${ }^{3}$, Zhengwu Huang ${ }^{1}$, Jun Wang ${ }^{2}$, Jianhua Piao ${ }^{1}$, Xiaoguang Yang ${ }^{1}$ and Lichen Yang ${ }^{1 *}$

\begin{abstract}
Background: Iron is a kind of essential trace mineral in the human body, while the studies on its physiological requirement are very limited recently, especially in China. And most studies were performed with the radioisotope tracer technique, which was harmful to health. This study aimed to first get the value of iron physiological requirements in Chinese adults assessed by the stable isotope labeling technique.

Methods: Forty-four eligible young Chinese healthy adults were randomly recruited from the Bethune Military Medical College (Shijiazhuang, Hebei, China) between January 2010 and March 2011, and 19 subjects were included in the final data analysis. After adaptive diets and observation, subjects received ${ }^{58} \mathrm{Fe}$ intravenously. The baseline venous blood sample and general information were collected on day 0 . Venous blood samples were also collected on day 14, 30, 60, 100, 120, $150,240,330,425,515,605,767,1155$, respectively. The blood samples were acid digested by a Microwave Digestion System and then analyzed by the MC-ICP-MS and Atomic Absorption Spectroscopy to get the abundance of Fe isotopes and the total iron concentration respectively. The circulation rate (the proportion of blood iron to whole body iron) could be calculated by the intake amount, background content and the peak isotope content. When the abundance changed stably, the iron physiological requirement could be calculated by the iron loss in a period of time.
\end{abstract}

Results: The abundance of ${ }^{58} \mathrm{Fe}$ reached its peak on day 14 , and changed stably from day 425 . The average circulation rate was 84\%, with no significance difference between the 2 genders. The mean iron requirement in females was 1101. $68 \mu \mathrm{g} / \mathrm{d}$, and the mean requirement adjusted by body weight was $20.69 \mu \mathrm{g} / \mathrm{kg} . \mathrm{d}$. For males, the mean iron requirement was $959.9 \mu \mathrm{g} / \mathrm{d}$, and the requirement adjusted by body weight was $14.04 \mu \mathrm{g} / \mathrm{kg} . \mathrm{d}$.

Conclusion: Our study has obtained the data about the iron physiological requirements of Chinese adults using stable isotope labeling technique, which could provide the basis for adjusting iron DRIs of Chinese people in the future.

Trial registration: The trial was registered at the Chinese Clinical Trial Registry (No: ChiCTR-TRC-09000581).

Keywords: Iron physiological requirements, Chinese adults, Stable isotope labeling technique

\section{Background}

Iron is the most abundant trace mineral in the human body, with an average of 3-4 g present in adults [1]. The main form of dietary iron intake in most countries is nonheme iron, which has a low absorption and utilization

\footnotetext{
*Correspondence: yanglichen28@126.com

'The Key Laboratory of Trace Element Nutrition of The Ministry of Health, National Institute for Nutrition and Health, Chinese Center for Disease Control and Prevention, 29 Nan Wei Road, Xicheng District, Beijing 100050, China

Full list of author information is available at the end of the article
}

rate. Iron deficiency anemia (IDA) can lead to developmental delays, behavioral disturbances, perinatal complications, and the impairment of learning ability and cognitive function $[2,3]$, which affects approximately onequarter of the world's population [4] and $9.7 \%$ of the population in China [5]. Meanwhile, iron overload may lead to various pathological clinical outcomes, such as pancreatic damage, cardiovascular disease, neurological disease and cancer [6-8].

Almost two-thirds of body iron is found in the hemoglobin present in circulating erythrocytes, other is 
contained in muscle tissue, iron store, and in variety of enzymes involved in oxidative metabolism and many other cell functions [9]. Evidence shows that iron balance in humans is dependent on variations in absorption other than excretion from the body [10,11]. The physiological requirement in adult males who have no significant change in weight is usually regarded equal to iron loss [12]. The iron requirement value is the core parameter of dietary reference intakes (DRIs), which could help people to reasonably plan their iron intake and maintain iron homeostasis.

The traditional methods used to research iron loss in adults are those such as the factorial method of calculating nutrient requirements, metabolic balance and radioisotope labeling method. The factorial calculation is an indirect method based on calculation which adds up all aspects of iron requirements. Metabolic balance is a classical method in the field of nutrition which requires simple testing equipment and easy operation. The balance test is often unable to obtain true and reliable data because the iron absorption rate may be either overestimated or underestimated [13]. The radioisotope tracer technique is simple, accurate, highly sensitive, and can be adopted during the normal physiological conditions of an organism. Since 1939, a series of studies on the iron requirements in human adults using the radioisotope tracer method have been carried out in western countries [14]. However, the radiation effect and finite choice of radioactive isotopes have limited their more application. With the development of technology, the stable isotope labeling technique, with its advantage of no radioactive health hazards to subjects, has been used for studying absorption and utilization rate of iron in recent years $[15,16]$, while rarely used in iron physiological requirements. A study using ${ }^{58} \mathrm{Fe}$ by Fomon in 2005 only focused on toddlers [17]. In studies conducted using radioactive isotopes, most of the subjects were adult males [18, 19], and the figures about women were very limited. In China, there is no direct experimental data from the domestic population and the values related to DRIs are all calculated based on experimental data from other countries.

In this study, we aimed to firstly obtain the value of iron physiological requirements in Chinese adults. Evidence shows that most iron in the body is combined with hemoglobin and exists in the circulatory system [10]. Iron physiological requirements could be calculated according to the change of isotope abundance in the blood. This experimental data related to the iron nutrition of Chinese adults can reflect the iron requirement of the Chinese population more accurately and help us to better update and adjust the DRIs in China. And this method for evaluating iron physiological requirement can be referred in the further studies.

\section{Methods}

\section{Location and experimental design}

We assumed that the proportion of blood iron to whole body iron, the circulating rate (usually called the erythrocyte incorporation rate in many studies), was approximately constant during the observation period. Then, the change of iron isotopic abundance in blood is consistent with the change in whole body. After the subjects had taken a certain amount of enriched ${ }^{58} \mathrm{Fe}$, the isotope content in the blood circulation reached its peak in a relatively short time. At this time, the circulating rate of iron was calculated according to the amount of the isotope absorbed and the content of the isotope in blood. Thereafter, the ${ }^{58} \mathrm{Fe}$ abundance in the blood gradually became diluted by the natural isotopic composition of iron having a higher abundance of ${ }^{56} \mathrm{Fe}$ than the blood. The smooth transition of abundance is known as the "stable period", marking the point when the labeled ${ }^{58} \mathrm{Fe}$ is fully mixed into the body. At this point, changes of iron isotopic abundance in blood can represent changes in the whole body. So, monitoring for over 3 years ensured that isotopic abundance had reached the stable period. Iron loss in circulation for a specific period of time during the stable period was obtained by accurately measuring the change ${ }^{58} \mathrm{Fe}$ abundances in the blood. In this way, the total iron loss in the human body, which is physiological requirement, was calculated combined with the circulating rate.

Forty-four eligible young Chinese healthy adults (22 women and 22 men) were randomly recruited from the Bethune Military Medical College (Shijiazhuang, Hebei, China) between January 2010 and March 2011. Subjects had not taken any mineral or vitamin supplements within 1 month before the study. Subjects were excluded under the following conditions: 1 . those who were infected with a disease that could affect iron absorption and metabolism (such as malabsorption, ulcer and inflammatory diseases) or under abnormal iron nutrition statuses; 2 . those who regularly took medication that could affect iron absorption and metabolism; 3 . women during pregnancy or menstruation.

At the beginning of the trial, the subjects received isotope ${ }^{57} \mathrm{Fe}$ and ${ }^{58} \mathrm{Fe}$ (the majority of ${ }^{57} \mathrm{Fe}$ orally and ${ }^{58} \mathrm{Fe}$ intravenously). By monitoring the first 14 days, our team obtained the absorption rate and the red cell utilization rate of non-heme iron, and the results of male have been published. Specific diet recipes and the preparation of isotopically labeled iron have also been described in detail in the previous article [20]. The women and men underwent the same procedure in this study, while the current article on women has not yet been published. Now, this article focused on the physiological requirements of iron, which was got by more than 3 years of monitoring the isotope abundance in subjects diluted. 
Baseline venous blood samples and general information were collected on day 0 . Venous blood samples were also collected on day 14, 30, 60, 100, 120, 150, 240, 330, 425, 515, 605, 767 and 1155, respectively. Throughout the follow-up, attention was paid to the health condition of all subjects to ensure that there were no traumatic blood loss and abnormal iron metabolism. The female menstrual period was avoided in the first 14 days of the experiment, while it could not be avoided for the whole follow-up over the 3 years. After the preliminary experiment, ${ }^{58} \mathrm{Fe}$ was considered more appropriate for the research of iron physiological requirements for its lower natural abundance and less interference. So we used only the abundances of ${ }^{58} \mathrm{Fe}$ in this part of study. The trial was registered at the Chinese Clinical Trial Registry (No: ChiCTR-TRC-09000581) and approved by the Ethics Committee of the National Institute of Nutrition and Health, Chinese Center for Disease Control and Prevention. The informed consent was also obtained from all subjects prior to participation.

\section{Analytical method}

Venous blood samples were collected by evacuated tubes containing K2-EDTA (BD, New Jersey, USA) and stored in a refrigerator $\left(-80^{\circ} \mathrm{C}\right)$. Before measuring, the blood samples were acid digested by a Microwave Digestion System (Mars 6, GEM, USA). The $0.5 \mathrm{~g}$ blood sample was mixed with $6 \mathrm{ml} 70 \% \mathrm{HNO}_{3}$ solution following the digestion procedure $\left(120^{\circ} \mathrm{C}\right.$ : ramp $6 \mathrm{~m}$, hold $5 \mathrm{~m} ; 150^{\circ} \mathrm{C}$ : ramp $5 \mathrm{~m}$, hold $15 \mathrm{~m} ; 190^{\circ} \mathrm{C}$ : ramp $5 \mathrm{~m}$, hold $30 \mathrm{~m}$; $1600 \mathrm{~W})$. The abundance of Fe isotopes was analyzed by the Multi-collector inductively-coupled plasma mass spectrometry (MC-ICP-MS) with a standard-sample bracketing method. All Fe isotopes were simultaneously detected together with ${ }^{60} \mathrm{Ni}$ as a monitor for the correction of isobaric interferences of ${ }^{58} \mathrm{Ni}$ on ${ }^{58} \mathrm{Fe}$ in one sequence. A mixture of argon and $\mathrm{H}_{2}$ were used as collision gas to eliminate the interferences [21]. Under optimized conditions, external precision of the order of 0.01-0.03\% (relative standard deviation, RSD), and 0 . $1-0.3 \%$ (RSD) was obtained for ${ }^{54} \mathrm{Fe} /{ }^{56} \mathrm{Fe},{ }^{57} \mathrm{Fe} /{ }^{56} \mathrm{Fe}$ and ${ }^{58} \mathrm{Fe} /{ }^{56} \mathrm{Fe}$, respectively. The abundance of ${ }^{58} \mathrm{Fe}$ were measured accordingly. Total iron concentration analysis was performed by the Atomic Absorption Spectroscopy (AAS) (PinAAcle 900, PerkinElmer). Biochemical assays for iron status of the serum ferritin (SF), unsaturated iron-binding capacity (UIBC), serum iron (SI), serum transferrin receptor (sTfR) and inflammation markers of C-reactive protein (CRP) were performed using an automatic biochemical analyzer (Hitach7180, Japan).

\section{Calculation method}

After the iron isotopes ${ }^{58} \mathrm{Fe}$ taken in test days were completely mixed with the iron in the body of the subjects and reached a stable state, the daily loss of iron was calculated by the change in iron isotope during a period of time (assuming day $i$ to day $i+t$ ). Since the subjects were in iron homeostasis, the total amount of iron in the body remained approximately constant, which meant the amount of daily requirement was relative invariant. According to the report by the USA National Academy Press in 2001, for the healthy men in iron homeostasis, the daily loss was equal to the daily requirement (assuming $\mathrm{R}$ in the formula) [12]. For women, blood loss in the menstruation would fluctuate the iron status in several days. To balance this effect, we collected blood samples away from their menstrual periods and chose a relative long period of time for calculation.

So, the isotopic content of iron in the whole body on day i minus the loss in $t$ days, plus the isotope of iron absorbed with natural abundance in $t$ days, was equal to the isotopic content of iron in the whole body on day $\mathrm{i}$ $+\mathrm{t}$. The formula can be deduced as follows:

$$
\begin{aligned}
\mathrm{T} & \times \mathrm{V} \times \mathrm{P}_{\mathrm{i}} \div \mathrm{C}-\mathrm{t} \times \mathrm{R} \times\left(\mathrm{P}_{\mathrm{i}}+\mathrm{P}_{\mathrm{i}+\mathrm{t}}\right) / 2+\mathrm{t} \\
& \times \mathrm{R} \times \mathrm{NA} \\
& =\mathrm{T} \times \mathrm{V} \times \mathrm{P}_{\mathrm{i}+\mathrm{t}} \div \mathrm{C}
\end{aligned}
$$

After formal transformation:

$$
\begin{aligned}
\mathrm{R}= & \mathrm{T} \times \mathrm{V} \times\left(\mathrm{P}_{\mathrm{i}}-\mathrm{P}_{\mathrm{i}+\mathrm{t}}\right) \div \mathrm{t} \\
& \div\left[\left(\mathrm{P}_{\mathrm{i}}+\mathrm{P}_{\mathrm{i}+\mathrm{t}}\right) / 2-\mathrm{NA}\right] \div \mathrm{C}
\end{aligned}
$$

$\mathrm{T}$ : the concentration of total iron in the blood $(\mathrm{mg} / \mathrm{L})$. $\mathrm{P}_{\mathrm{i}}$ : the isotopic abundance on day $\mathrm{i}$.

NA: the natural abundance of isotopes.

t: total number of days in the period of time which recorded for calculation.

R: daily loss or intake of iron (mg).

$\mathrm{C}$ : the circulation rate (the proportion of iron in the blood to total iron in the body).

Table 1 The demographic information of subjects with complete data

\begin{tabular}{lllllll}
\hline & $\mathrm{n}$ & age & height $(\mathrm{cm})$ & weight $(\mathrm{kg})$ & BMl $\left(\mathrm{kg} / \mathrm{cm}^{2}\right)$ & ${ }^{58} \mathrm{Fe} \mathrm{received}(\mathrm{mg})$ \\
\hline female & 10 & $22 \pm 1$ & $163.40 \pm 3.37$ & $51.3 \pm 4.9$ & $19.20 \pm 1.80$ & $3.70 \pm 0.17$ \\
male & 10 & $23 \pm 1$ & $171.70 \pm 3.86$ & $64.1 \pm 8.9$ & $21.75 \pm 2.93$ & $4.93 \pm 0.52$ \\
total & 20 & $22 \pm 1$ & $167.55 \pm 5.53$ & $57.7 \pm 9.6$ & $20.48 \pm 2.70$ & $4.31 \pm 0.73$ \\
\hline
\end{tabular}




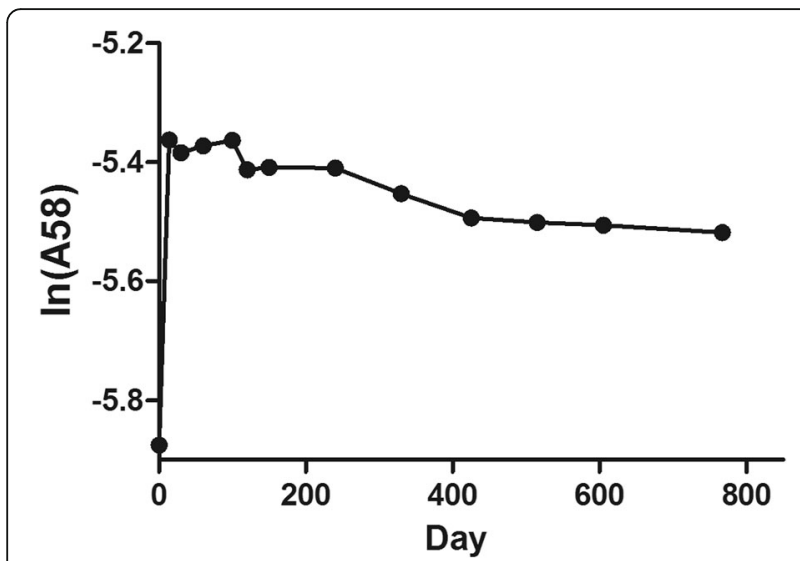

Fig. 1 The abundance change of ${ }^{58} \mathrm{Fe}$

V: blood volume (L), which was by the formula published by Carlsen and Bruun [22], V $(\mathrm{ml})=(45.2+$ $25.3 \times$ exp. $(-0.0198 \times \mathrm{DDW})) \times \mathrm{BW}(\mathrm{kg})$, where DDW $=$ $100 \times(\mathrm{BW}(\mathrm{kg})-7.582 \times \exp .(0.01309 \times \mathrm{BH} \quad(\mathrm{cm}))) \quad / \quad 7$. $582(0.01309 \times \mathrm{BH}(\mathrm{cm}))$.

The circulation rate can be calculated by the quantity of administered isotope in the blood and the total amount of administered isotope. The administrated ${ }^{58} \mathrm{Fe}$ in the blood was calculated by the following formula described in the article by Steven A Abrams [23]:

$$
\begin{aligned}
{ }^{58} \mathrm{Fe}_{\text {inc }}= & {\left[{ }^{58} \mathrm{Fe} /{ }^{56} \mathrm{Fe}_{\mathrm{enr}}-{ }^{58} \mathrm{Fe} /{ }^{56} \mathrm{Fe}_{\text {base }}\right] \times \mathrm{Fe}_{\text {circ }} } \\
& \times \mathrm{NA}_{58} \div\left({ }^{58} \mathrm{Fe} /{ }^{56} \mathrm{Fe}_{\text {base }}\right)
\end{aligned}
$$

${ }^{58} \mathrm{Fe}_{\text {inc }}$ : the quantity of administered ${ }^{58} \mathrm{Fe}$ in the blood (mg).

${ }^{58} \mathrm{Fe} /{ }^{56} \mathrm{Fe}_{\text {enr }}:{ }^{58} \mathrm{Fe} /{ }^{56} \mathrm{Fe}$ on its peak day (day 14) measured by $\mathrm{MC}$-ICP-MS.

${ }^{58} \mathrm{Fe} /{ }^{56} \mathrm{Fe}_{\text {base }}:{ }^{58} \mathrm{Fe} /{ }^{56} \mathrm{Fe}$ on day 0 measured by $\mathrm{MC}$ ICP-MS.

$\mathrm{Fe}_{\text {circ: }}$ : the total iron in circulation $(\mathrm{mg})$, which was calculated by blood volume and concentration of total iron in the blood measured by AAS.

$\mathrm{NA}_{58}$ : the natural abundance of ${ }^{58} \mathrm{Fe}$.

\section{Statistical analysis}

General statistical analysis was performed using SPSS version 19.0. The normality of the data distribution of the tests under study was investigated with the KolmogorovSmirnoff test. CRP and sTfR did not obey normal distribution, so they were expressed as median (P25, P75), other variables were expressed as means \pm standard deviations $(\overline{\mathrm{X}} \pm S D)$. The differences between the two genders were compared by $\mathrm{t}$ test. The time when the change of isotopic abundance became stable was determined by the Repeated Measures Analysis of Variance Analysis (RMANOVA) combined with the line chart of the change. Comparison of iron nutritional status at different time points was also performed by RMANOVA. The rank sum test was used when comparing CRP and sTfR on different days. The $t$ test and RMANOVA were performed by SAS version 9.4 , and $P$ values less than 0.05 were considered statistically significant.

\section{Results}

\section{Identification of the stable period}

After receiving ${ }^{58} \mathrm{Fe}$, follow-up monitoring of the subjects was conducted for more than 3 years. Twenty subjects (10 female and 10 male) with complete data of 13 blood samples (day 0, 14, 30, 60, 100, 120, 150, 240, 330, $425,515,605,767)$ were used to identify the stable period, and their information is presented in Table 1. The mean age of the subjects was 22, ranging from 20 to 25. The mean height, weight and BMI was $167.55 \mathrm{~cm}$, $57.7 \mathrm{~kg}$ and $20.48 \mathrm{~kg} / \mathrm{cm}^{2}$, respectively.

On day 0 , the mean abundance of ${ }^{58} \mathrm{Fe}$ was 0.002809 , which was very close to the natural abundance. Because the decrease of isotopic tracer in the blood after the stable period is exponential, the abundance of ${ }^{58} \mathrm{Fe}$ was $\log$ transformed (natural logarithm) to help judgment. The changes of isotopic abundance $\left(\ln \mathrm{A}\left({ }^{58} \mathrm{Fe}\right)\right)$ in blood are shown in Fig. 1. After the injection of artificially enriched ${ }^{58} \mathrm{Fe}$, its abundance in the blood peaked dramatically (on day 14). The curve then fluctuated for a period of time until eventually stabilizing. From observation, we found the change of ${ }^{58} \mathrm{Fe}$ became smooth and reached the stable period from day 425.

Polynomial comparison of RMANOVA was also used to help determine the stable period (Table 2). Some periods of time with the log-transformed abundance were intercepted to see if the first and second degree polynomial contrast were meaningful in the comparison. The results showed that the curve appears a linear trend from day 120-767, while the curve trend also came from day 240767. Until day 330, the real linear trend appears. And from

Table $2 P$ values of polynomial contrast by RMANOVA

\begin{tabular}{llllllllll}
\hline & start(day) & 60 & 100 & 120 & 150 & 240 & 330 & 425 & 515 \\
& over (day) & 767 & 767 & 767 & 767 & 767 & 767 & 767 & 767 \\
\hline Ln( A $\left.^{58} \mathrm{Fe}\right)$ & time_1 $^{*}$ & $<0.0001$ & $<0.0001$ & 0.0009 & 0.0014 & 0.0004 & 0.0004 & 0.2178 & 0.4797 \\
& time_2* $^{*}$ & 0.0321 & 0.0063 & 0.0748 & 0.0699 & 0.0457 & 0.2600 & 0.9708 & 0.9450 \\
\hline
\end{tabular}

*time_N represents the $\mathrm{nth}$ degree polynomial contrast for time 
Table 3 The circulation rate of subjects

\begin{tabular}{lllll}
\hline & $\mathrm{n}$ & weight $(\mathrm{kg})$ & age & circulation rate(\%) \\
\hline female & 21 & $54.6 \pm 6.82$ & $22.24 \pm 1.03$ & $82.80 \pm 12.55$ \\
male & 19 & $67.43 \pm 12.20$ & $22.56 \pm 1.00$ & $85.46 \pm 7.71$ \\
total & 40 & $60.7 \pm 11.60$ & $22.38 \pm 1.02$ & $84.06 \pm 10.49$ \\
\hline
\end{tabular}

day 425 , the abundance changed so slightly that the linear trend was not recognized by SAS. Therefore, it was conservative to consider that the stable period started from day 425 through synthetical consideration.

\section{The circulation rate}

The abundance of ${ }^{58} \mathrm{Fe}$ in the blood peaked on day 14 . The circulation rates of subjects are shown in Table 3 . In this part, of the 44 subjects enrolled, 1 subject dropped out before day 14, while the results of 3 subjects were significantly abnormal and removed of the final statistical analysis. The results of 40 subjects were included. The average circulation rate was $84.06 \%$, with no significance difference between the 2 genders.

\section{The iron physiological requirements}

Because the stable period started from day 425, we used the data after day 425 to calculate the iron daily requirement. Until day 425, 18 subjects could not be monitored for follow up (due to leaving the study, loss of contact, inability to obtain a blood sample, etc), and the abundance curves of 5 subjects changed abnormally (due to unknown reasons, excluding trauma, bleeding, and abnormal metabolic conditions) and the data from them could not be included for calculation. Twenty-one subjects was included for calculation, and 2 outliers were eliminated (out of mean \pm 3 standard deviation). Ultimately, the results of 19 subjects were included in the final data analysis. The iron daily requirement of subjects was calculated by the formula (1-b), with the data on day 515, 605, 767 and 1155 . Due to the difficulty in sample collection and cohort following for such a long time, 4 lots of blood samples were not received from every subject. In theory, the average daily loss of iron should be approximately equal at different periods of time after the stable period was reached. Thus, we selected the most suitable period of time for calculation according to the abundance curve of every subject. The calculation results from different data sources are shown in Table 4, and mean requirements between 2 genders are also compared in Table 5. Bar charts describing the iron requirements from different gender and data sources are illustrated in Figs. 2 and 3.

The mean body weight was $53.72 \mathrm{~kg}$ for females and $67.38 \mathrm{~kg}$ for males, with significant difference between the 2 genders $(t=-2.517, P=0.022)$. The mean iron requirement in females was $1101.68 \mu \mathrm{g} / \mathrm{d}$, and the mean requirement adjusted for body weight was $20.69 \mu \mathrm{g} / \mathrm{kg} . \mathrm{d}$. Both results from different data sources showed no significant difference. For males, the mean iron requirement was $959.9 \mu \mathrm{g} / \mathrm{d}$, and the requirement adjusted for body weight was $14.04 \mu \mathrm{g} / \mathrm{kg}$.d. Again, there was no significant difference from different data sources. The mean iron daily requirement adjusted for body weight showed significant difference between the two genders $(t=2.771$, $P=0.013)$.

Biochemical assays of iron status (sTfR, SF, UIBC, SI) and inflammation markers (CRP) were measured with the serum on day 0,767 and 1155. Throughout the study, the iron status of subjects were about normal. And for each index, there is no statistical difference of different time points $(P>0.05)$ (Table 6).

\section{Discussion}

To obtain the more reliable result, we assumed that the total amount of body iron of each subject was stable during the whole study. If the object was in the condition of bleeding, pregnancy and childbirth, it might affect the metabolism and amount body iron. In case the misestimates caused by these conditions, we have monitored the iron nutritional status of all subjects and ensured that they were all in the iron homeostasis. In order to ensure that the ${ }^{58} \mathrm{Fe}$ was fully mixed in the body, we combine the result of RMANOVA with the curve trend, and finally chose the more conservative result.

Table 4 The iron physiological requirements of different data sources

\begin{tabular}{|c|c|c|c|c|c|c|c|c|c|}
\hline \multirow[t]{3}{*}{ gender } & \multirow{3}{*}{$\begin{array}{l}\text { data } \\
\text { source }^{a}\end{array}$} & \multirow[t]{3}{*}{$\mathrm{n}$} & \multirow{3}{*}{$\begin{array}{l}\text { mean body } \\
\text { weight } \\
(\mathrm{kg})\end{array}$} & \multicolumn{3}{|c|}{ iron requirements $(\mu \mathrm{g} / \mathrm{d})$} & \multicolumn{3}{|c|}{ iron requirements adjusted by weight ( $\mu \mathrm{g} / \mathrm{kg} . \mathrm{d}$ ) } \\
\hline & & & & \multirow[t]{2}{*}{ mean \pm std } & \multicolumn{2}{|c|}{ comparison of different data source } & \multirow[t]{2}{*}{ mean \pm std } & \multicolumn{2}{|c|}{ comparison of different data source } \\
\hline & & & & & $\bar{F}$ & $P$ & & $\mathrm{~F}$ & $P$ \\
\hline \multirow[t]{3}{*}{ female } & A & 3 & $49.98 \pm 3.59$ & $877.11 \pm 352.09$ & 2.37 & 0.209 & $17.59 \pm 7.13$ & 0.594 & 0.594 \\
\hline & B & 1 & 48.28 & 993.4 & & & 20.58 & & \\
\hline & C & 3 & $59.28 \pm 12.31$ & $1362.34 \pm 175.52$ & & & $23.83 \pm 6.9$ & & \\
\hline \multirow[t]{2}{*}{ male } & B & 2 & $58.76 \pm 0.14$ & $846.65 \pm 125.97$ & 0.199 & 0.665 & $14.41 \pm 2.11$ & 0.018 & 0.896 \\
\hline & C & 10 & $69.1 \pm 13.08$ & $982.55 \pm 412.39$ & & & $13.97 \pm 4.38$ & & \\
\hline
\end{tabular}

${ }^{a}$ A: day 515 to day 767, B: day 605 to day 767, C: day 767 to day 1155 
Table 5 The iron physiological requirements between 2 genders

\begin{tabular}{|c|c|c|c|c|c|c|c|c|}
\hline \multirow[t]{3}{*}{ gender } & \multirow[t]{3}{*}{$\mathrm{n}$} & \multirow{3}{*}{$\begin{array}{l}\text { mean body } \\
\text { weight } \\
(\mathrm{kg})\end{array}$} & \multicolumn{3}{|c|}{ iron requirements $(\boldsymbol{\mu} \mathrm{g} / \mathrm{d})$} & \multicolumn{3}{|c|}{ iron requirements adjusted by weight ( $\boldsymbol{\mu g} / \mathrm{kg} . \mathrm{d})$} \\
\hline & & & \multirow[t]{2}{*}{ mean \pm std } & \multicolumn{2}{|c|}{ comparison of different genders } & \multirow[t]{2}{*}{ mean \pm std } & \multicolumn{2}{|c|}{ comparison of different gender } \\
\hline & & & & $\bar{T}$ & $P$ & & $\overline{\mathrm{T}}$ & $P$ \\
\hline female & 7 & $53.72 \pm 9.06$ & $1101.68 \pm 335.76$ & 0.819 & 0.424 & $20.69 \pm 6.53$ & 2.771 & 0.013 \\
\hline male & 12 & $67.38 \pm 12.5$ & $959.9 \pm 378.66$ & & & $14.04 \pm 4.02$ & & \\
\hline
\end{tabular}

The change of Fe isotopic abundance in blood indirectly reflected the distribution and metabolism of iron in the body. The mean abundance of ${ }^{58} \mathrm{Fe}$ on day 0 were very close to the natural abundance, proving the accuracy of the detection to a certain extent. After a series of transportation and metabolic processes, the iron intake in the test was fully mixed with the iron in the body and redistributed to a steady state. Some of the iron was bound to transferrin and then transported to the bone marrow for the hemoglobin synthesis in developing erythroid cells, which was the most important iron pool and had the highest turnover. The reticulocytes were released in to circulation from this site and became mature red cells with a lifespan of 120 days [8]. After 120 days, the iron released form the dead red cells would be recycled [10]. Because of these metabolic processes, it took some time for iron to reach the steady state, so we needed to find the stable period and calculate the iron daily requirement afterwards.

Our results show that the stable period started from day 425. A study by Hiroshi Saito et al. in 1964 reached the conclusion that the stable period was from day 360 [19]. In their study, 12 men were enrolled and injected with radioactive isotope ${ }^{59} \mathrm{Fe}$. And in a study used ${ }^{58} \mathrm{Fe}$ by Fomon in 2005, the subjects of which were toddlers, the stable period was from the 13th month (nearly day

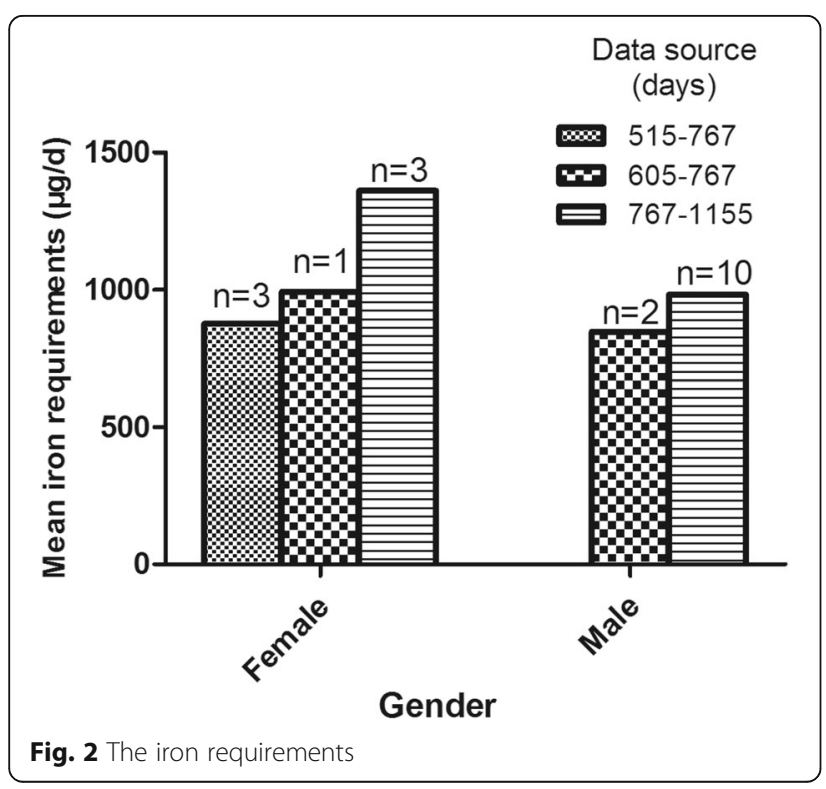

390) [17]. Our result of day 425 was a little later than their results, which may be due to the different subjects used and experimental design.

The majority of total body iron is present in hemoglobin in circulating erythrocytes [8], while its accurate proportion still lacks consensus. This proportion, which we called the circulating rate, was actually equal to the erythrocyte incorporation rate mentioned in other studies because the formulas were to calculate the ratio of ${ }^{58} \mathrm{Fe}$ in the blood compared to the ${ }^{58} \mathrm{Fe}$ administrated. In the article published by our group in 2016 [20], the ${ }^{58} \mathrm{Fe}$ incorporation rate of males was $85 \%$, consistent to our rate of $85.46 \%$. While in this paper, the concentration of total iron in blood was measured by AAS, which might be more accurate than previous studies using hemoglobin concentration as an estimate. Furthermore, in this paper we used isotopic abundance in whole blood for calculation whilst using isotopic abundance in red blood cell samples in the previous article. Many other studies also obtained the circulating rate. Hiroshi Saito et al. in 1964 enrolled 12 men in a study and reported that the average utilization of radio iron was $90 \%$, and $10 \%$ remained in tissues [19]. Larsen L in 1975 reported that mean red cell utilization of absorbed ${ }^{59} \mathrm{Fe}$ was $92.9 \%$ in adults [24]. Both of these studies used the radioactive isotope ${ }^{59} \mathrm{Fe}$. However, many studies showed that this rate was lower in infants (less than 80\%) compared with adults

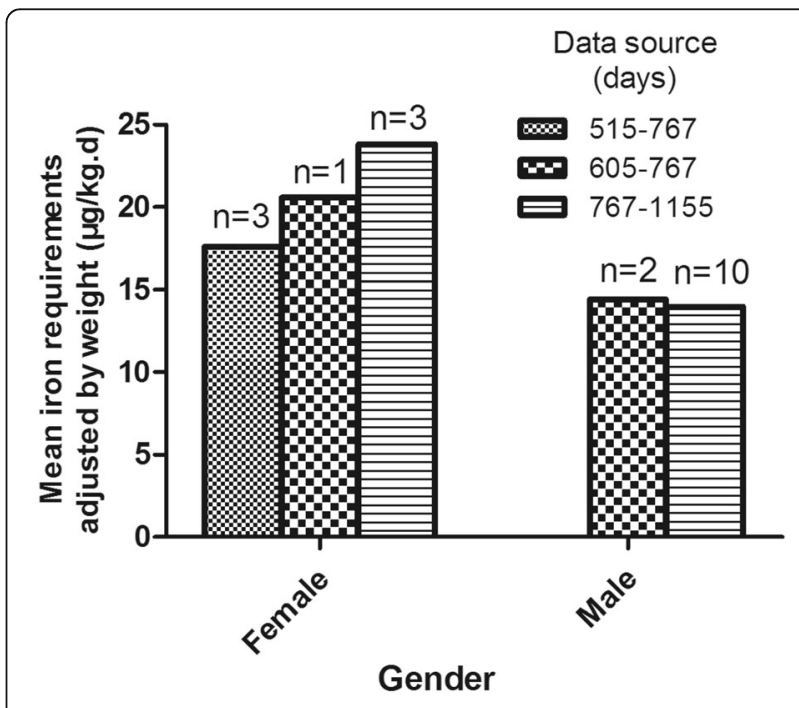

Fig. 3 The iron requirements adjusted by weight 
Table 6 Iron nutritional status

\begin{tabular}{lllllll}
\hline Day & $\mathrm{n}$ & $\mathrm{SF}(\mathrm{ug} / \mathrm{L})$ & $\mathrm{UIBC}(\mathrm{umol} / \mathrm{L})$ & $\mathrm{SI}(\mathrm{umol} / \mathrm{L})$ & $\mathrm{sTfR}(\mathrm{g} / \mathrm{L})$ & $\mathrm{CRP}(\mathrm{mg} / \mathrm{L})$ \\
\hline 0 & 19 & $74.8 \pm 54.5$ & $24.7 \pm 9.4$ & $17.8 \pm 6.1$ & $2.6(2.19,3.08)$ & $0.1(0,0.3)$ \\
767 & 17 & $101.3 \pm 54.5$ & $27.2 \pm 8.2$ & $18.5 \pm 5.8$ & $2.21(1.94,2.35)$ & $0.3(0.1,0.5)$ \\
1155 & 12 & $103.4 \pm 44.2$ & $29 \pm 7.8$ & $20.9 \pm 6$ & $2.37(2.17,2.6)$ & $0.5(0.2,0.8)$ \\
Statistics & & $\mathrm{F}=2.787$ & $\mathrm{~F}=0.502$ & $\mathrm{~F}=1.971$ & $X^{2}=1.000$ & $X^{2}=4.471$ \\
$P$ value & 0.092 & 0.615 & 0.190 & 0.607 & 0.107 \\
\hline
\end{tabular}

[25]. Zlotkin et al. [26] and McDonald et al. [27] reported that the ${ }^{58} \mathrm{Fe}$ incorporation rate was $75 \%$ and $68 \%$ in preterm infants, respectively. This difference might be explained by the fact that the cell synthesis in infants was more active than that in adults.

Due to the long follow up time and difficulty of continuous blood sample collecting in this study, it was relatively hard to maintain data for all the subjects and the data that could be used for calculation was also limited. Of the 19 subjects finally included in the statistical analysis, the results of 12 males were close to that of Seattle whites $(0.95 \mathrm{mg} / \mathrm{d}, 12.1 \mu \mathrm{g} / \mathrm{kg} . \mathrm{d})$, Durban Indians (1. $02 \mathrm{mg} / \mathrm{d}, 16.4 \mu \mathrm{g} / \mathrm{kg} . \mathrm{d})$ and Araya Mestizos $(0.90 \mathrm{mg} / \mathrm{d}$, $13.3 \mu \mathrm{g} / \mathrm{kg} . \mathrm{d})$ in the study by Green et al. in 1968 [18], and the present Chinese DRIs of iron were calculated based on its results, which only reported iron loss in men. Before this study, Finch et al. calculated that daily iron loss was approximately $0.61 \mathrm{mg} / \mathrm{d}$ in men (mean weight $66 \mathrm{~kg}$ ), $0.64 \mathrm{mg} / \mathrm{d}$ in non-menstruating women (mean weight $59 \mathrm{~kg}$ ) and $1.22 \mathrm{mg} / \mathrm{d}$ in menstruating women (mean weight $61 \mathrm{~kg}$ ) [28]. In our data, the real different iron requirements of the 2 genders were covered by the different mean body weight, so a significantly higher requirement for iron appeared in women after adjustments for body weight. In this study, we avoided menstruation during the test days (day 0 to day 14) and pregnancy and fertility during the entire experimental period (day 0 to day 1155), whilst menstruation might not be avoided during the long follow up time. So, the results we calculated from women were supposed to contain the loss during the menstrual period. This might be the main reason for the different requirements between males and females. Our result of women was consistent with that described in the report published by American national academy press in 2001 [12]. In the report, the iron requirements for women were estimated by customary two-component model, consisting of basal losses and menstrual losses. The median iron requirement for women was $1.4 \mathrm{mg} / \mathrm{d}$, while the mean weight of subjects for calculating basal losses was $64 \mathrm{~kg}$. Some studies have reported lower figures than us. Hiroshi Saito et al. in 1964 [19], using a whole body isotopic retention technique, reported that daily iron loss was of 0 . $89 \mathrm{mg} / \mathrm{d}$ in $12 \mathrm{men}$. In 2005, Fomon et al. used ${ }^{58} \mathrm{Fe}$ to research the iron loss of toddlers. From 13 to 26 months of age, the daily inevitable iron loss was $0.25 \mathrm{mg} / \mathrm{d}$ (mean weight was $10.3 \mathrm{~kg}$ in 13 month and $13.1 \mathrm{~kg}$ in 26 month) [17]. This daily iron loss adjusted by weight of toddlers is similar to that of our female subjects. Changes in people's nutritional status, as well as differences in populations and methods of experimentation, may all contribute to the differences in outcome. Overall, however, our results were approximately in line with other studies. The main limitation of our study was that fewer cases could be used for calculation, especially for women. We will further validate the results in the future.

\section{Conclusion}

Our study firstly used the stable isotope technique to study iron physiological requirements. We obtained data about the daily iron requirement of Chinese adults, relatively consistent with other studies, which could provide the basis for adjusting iron DRIs in the future.

\section{Abbreviations \\ AAS: Atomic Absorption Spectroscopy; CRP: C-reactive protein; DRls: Dietary reference intakes; IDA: Iron deficiency anemia; MC-ICP-MS: Multi-collector inductively-coupled plasma mass spectrometry; RMANOVA: Repeated Measures Analysis of Variance Analysis; RSD: Relative standard deviation; SF: Serum Ferritin; SI: Serum Iron; sTfR: serum Transferrin receptor; \\ UIBC: Unsaturated Iron-Binding Capacity}

\section{Acknowledgements}

Not applicable.

\section{Funding}

This project was supported by the National Natural Science Foundation of China (https://isisn.nsfc.gov.cn/egrantindex/funcindex/prjsearch-list, grant no.:81330066) \& Technology Pillar Program during the Eleventh Five-Year Plan Period (grant no.: 2008BA158B02).

\section{Availability of data and materials}

The datasets used and/or analyzed during the current study are available from the corresponding author on reasonable request.

\section{Authors' contributions}

Conceived and designed the experiments: LY ZH JP XY. Performed the experiments: LY YZ LG ZW JW TR JC. Analyzed the data: JC. Contributed reagents/materials/analysis tools: JW TR. Wrote the paper: JC. All authors read and approved the final manuscript.

\section{Ethics approval and consent to participate}

The trial was approved by the Ethics Committee of the National Institute of Nutrition and Health, Chinese Centers for Disease Control and Prevention.

The informed consent was also obtained from all subjects prior to participation.

Consent for publication

Not applicable. 


\section{Competing interests}

The authors declare that they have no competing interests.

\section{Publisher's Note}

Springer Nature remains neutral with regard to jurisdictional claims in published maps and institutional affiliations.

\section{Author details}

${ }^{1}$ The Key Laboratory of Trace Element Nutrition of The Ministry of Health, National Institute for Nutrition and Health, Chinese Center for Disease Control and Prevention, 29 Nan Wei Road, Xicheng District, Beijing 100050, China. ${ }^{2}$ National Institute of Metrology, National Research Center for Certified Reference Material, No.18, Bei San Huan Dong Lu, Chaoyang Dist, Beijing, People's Republic of China. ${ }^{3}$ Bethune Military Medical College, Zhongshanx Road 450, Shijiazhuang, Hebei province, China.

\section{Received: 29 November 2017 Accepted: 23 March 2018}

\section{Published online: 20 April 2018}

\section{References}

1. Lim KH, Riddell LJ, Nowson CA, Booth AO, Szymlek-Gay EA. Iron and zinc nutrition in the economically-developed world: a review. Nutrients. 2013 5(8):3184-211.

2. Kiudeliene R, Griniute R, Labanauskas L. Prognostic value of reticulocyte hemoglobin content to diagnose iron deficiency in 6-24-month-old children. Medicina (Kaunas). 2008;44(9):673-7.

3. Hempel EV, Bollard ER. The evidence-based evaluation of Iron deficiency Anemia. Med Clin North Am. 2016:100(5):1065-75.

4. McLean E, Cogswell M, Egli I, Wojdyla D, de Benoist B. Worldwide prevalence of anaemia, WHO vitamin and mineral nutrition information system, 1993-2005. Public Health Nutr. 2009;12(4):444-54.

5. Chang J, Wang Y. Monitoring of nutritional and health status of Chinese residents: a comprehensive report for 2010-2013 years. 1st ed. Beijing: Peking University Medical Press; 2016.

6. Santos GA, Cruzado VL, Macias CN, Linares GT, Rodriguez FM. Unnoticed iron overload leading to irreversible pancreatic damage. Nefrologia. 2017; DOl: https://doi.org/10.1016/j.nefro.2017.05.001. (Epub ahead of print).

7. Ribeiro JR, Marques VB, Nunes DO, Stefanon I, Dos SL. Chronic iron overload induces functional and structural vascular changes in small resistance arteries via NADPH oxidase-dependent O2- production. Toxicol Lett. 2017; 279:43-52.

8. Lieu PT, Heiskala M, Peterson PA, Yang Y. The roles of iron in health and disease. Mol Asp Med. 2001;22(1-2):1-87.

9. Abbaspour N, Hurrell R, Kelishadi R. Review on iron and its importance for human health. J Res Med Sci. 2014:19(2):164-74.

10. Wallace DF. The regulation of Iron absorption and homeostasis. Clin Biochem Rev. 2016:37(2):51-62.

11. Hurrell R, Egli I. Iron bioavailability and dietary reference values. Am J Clin Nutr. 2010;91(5):1461S-7S.

12. Food and Nutrition Board, Institute of Medicine. Dietary reference intakes for vitamin a, vitamin $\mathrm{K}$, arsenic, boron, chromium, copper, iodine, Iron, manganese, molybdenum, nickel, silicon, vanadium, and zinc. Washington, DC: National Academy Press; 2001.

13. Cook JD, Layrisse M, Martinez-Torres C, Walker R, Monsen E, Finch CA. Food iron absorption measured by an extrinsic tag. J Clin Invest. 1972; 51(4):805-15.

14. Hahn PF, Bale WF, Lawrence EO, Whipple GH. Radioactive iron and its metabolism in anemia: its absorption, transportation, and utilization. J Exp Med. 1939;69(5):739-53.

15. Szymlek-Gay EA, Domellöf M, Hernell O, Hurrell RF, Lind T, Lönnerdal B, Zeder C, Egli IM. Mode of oral iron administration and the amount of iron habitually consumed do not affect iron absorption, systemic iron utilisation or zinc absorption in iron-sufficient infants: a randomised trial. $\mathrm{Br} \mathrm{J}$ Nutr. 2016;116(6):1046-60

16. Zlotkin SH, Schauer C, Owusu Agyei S, Wolfson J, Tondeur MC, Asante KP, Newton S, Serfass RE, Sharieff W. Demonstrating zinc and iron bioavailability from intrinsically labeled microencapsulated ferrous fumarate and zinc gluconate sprinkles in young children. J Nutr. 2006;136(4):920-5

17. Fomon SJ, Nelson SE, Serfass RE, Ziegler EE. Absorption and loss of iron in toddlers are highly correlated. J Nutr. 2005;135(4):771-7.
18. Green R, Charlton R, Seftel H, Bothwell T, Mayet F, Adams B, Finch C, Layrisse M. Body iron excretion in man: a collaborative study. Am J Med. 1968:45(3):336-53.

19. SAITO H, SARGENT TR, PARKER HG, LAWRENCE JH. WHOLE-BODY IRON LOSS IN NORMAL MAN MEASURED WITH A GAMMA SPECTROMETER. J Nucl Med. 1964;5:571-80.

20. Yang L, Zhang Y, Wang J, Huang Z, Gou L, Wang Z, Ren T, Piao J, Yang X. Non-Heme Iron absorption and utilization from typical whole Chinese diets in young Chinese urban men measured by a double-labeled stable isotope technique. PLoS One. 2016;11(4):e0153885.

21. Zhou T, Zhao M, Wang J, Lu H. Absolute measurements and certified reference material for iron isotopes using multiple-collector inductively coupled mass spectrometry. Rapid Commun Mass Spectrom. 2008:22(5):717-20.

22. Carlsen $\mathrm{O}$, Bruun P. A method for determination of normal or abnormal blood volume in patients subjected to radionuclide cardiography. Scand J Clin Lab Invest. 1990;50(1):63-7.

23. Abrams SA. Using stable isotopes to assess mineral absorption and utilization by children. Am J Clin Nutr. 1999;70(6):955-64.

24. Larsen L, Milman N. Normal iron absorption determined by means of whole body counting and red cell incorporation of 59Fe. Acta Med Scand. 1975; 198(4):271-4.

25. Fomon SJ, Ziegler EE, Serfass RE, Nelson SE, Rogers RR, Frantz JA. Less than $80 \%$ of absorbed iron is promptly incorporated into erythrocytes of infants. Nutr. 2000:130(1):45-52.

26. Tondeur MC, Schauer CS, Christofides AL, Asante KP, Newton S, Serfass RE, Zlotkin SH. Determination of iron absorption from intrinsically labeled microencapsulated ferrous fumarate (sprinkles) in infants with different iron and hematologic status by using a dual-stable-isotope method. Am J Clin Nutr. 2004 Nov;80(5):1436-44.

27. McDonald MC, Abrams SA, Schanler RJ. Iron absorption and red blood cell incorporation in premature infants fed an iron-fortified infant formula. Pediatr Res. 1998 Oct;44(4):507-11.

28. Finch CA. Body iron exchange in man. J Clin Invest. 1959:38(2):392-6.

\section{Submit your next manuscript to BioMed Central and we will help you at every step:}

- We accept pre-submission inquiries

- Our selector tool helps you to find the most relevant journal

- We provide round the clock customer support

- Convenient online submission

- Thorough peer review

- Inclusion in PubMed and all major indexing services

- Maximum visibility for your research

Submit your manuscript at www.biomedcentral.com/submit
Biomed Central 